\title{
DURABILIDADE NATURAL DE QUATRO ESPÉCIES FLORESTAIS EM CAMPO DE APODRECIMENTO
} Andressa Jaqueline Tomazeli ${ }^{1 *}$, Amanda Grassmann da Silveira ${ }^{2}$, Rômulo Trevisan ${ }^{3}$, Arci Dirceu Wastowski ${ }^{3}$, Gabriel Valim Cardoso 4 .

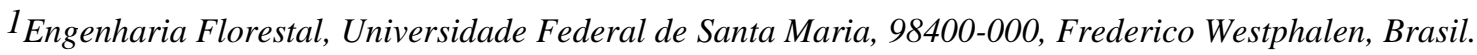

2 Pós-Graduação, Universidade Federal de Santa Maria, 97105-900, Santa Maria, Brasil.

3 Professor Adjunto, Universidade Federal de Santa Maria, 98400-000, Frederico Westphalen, Brasil.

4 ProfessorAssistente, Universidade Federal de Pelotas, 96010290, Pelotas, Brasil.

*E-mail: andressatomazeli@hotmail.com

\section{RESUMO}

O objetivo do trabalho foi avaliar a durabilidade natural de quatro espécies florestais (Pinus elliottii, Acacia mearnsii, Hovenia dulcis e Melia azedarach) em campo de apodrecimento. O experimento foi implantado no município de Frederico Westphalen - RS, sendo utilizadas 20 árvores, 5 para cada espécie analisada, as quais foram transformadas em moirões roliços enterrados a uma profundidade de $40 \mathrm{~cm}$ do solo. Nos períodos 0,6 e 12 meses foram retirados discos para a determinação do teor de umidade e realização de análises químicas. Com inspeções mensais a campo, foram realizadas avaliações visuais para verificar o estado das peças e o desenvolvimento de organismos xilófagos. Em laboratório, a determinação do grau de deterioração foi realizada através da solubilidade da madeira em hidróxido de sódio a $1 \%$. Os procedimentos foram realizados em triplicata e analisados estatisticamente pelo teste DMS a 5\% de probabilidade de erro. Os resultados mostraram que o teor de umidade manteve-se alto ao longo do experimento. Nas avaliações visuais foi constatada a ocorrência de um único fungo, Pycnoporus sanguineus, na Acacia mearnsii e Pinus elliottii. O tempo de exposição causou variações consideráveis na composição química das espécies indicado pelo aumento da solubilidade da madeira.

Palavras-chave: Solubilidade. Extrativos. Xilófagos. Umidade. Deterioração.

\section{Introdução}

A madeira, por suas propriedades particulares, é um material que desde os primórdios colaborou no desenvolvimento das civilizações. A resistência mecânica elevada, a facilidade de manuseio, uma resistência química apreciável, um bom isolante elétrico e térmico, a possibilidade de ser encontrada na natureza com ampla variedade, além do baixo consumo de energia para o seu processamento, fizeram da madeira uma das maiores ferramentas usadas e desejadas pelo homem [1].

A durabilidade natural da madeira permite avaliar a vida média útil e a susceptibilidade aos agentes deterioradores, incluindo biológicos, físicos e químicos. No entanto, em virtude da frequência e da importância econômica, a resistência natural é normalmente entendida como referente aos agentes biológicos [2]. Para Botelho et al. [3], esta característica varia substancialmente entre as espécies, inclusive, dentro da mesma árvore, portanto o seu estudo assume significativa importância na identificação das potencialidades e usos finais das madeiras.
Além da variação dentro da mesma árvore, há registros de grandes diferenças entre a resistência de árvores de uma mesma espécie, o que pode ser proveniente do potencial genético de cada indivíduo [4].

Os resultados obtidos em ensaios de campo com madeiras em contato direto com o solo possibilitam a classificação da sua durabilidade, recomendando-se ou não o seu uso em ambientes externos [5]. Em condições favoráveis, todas as espécies florestais são suscetíveis ao ataque de organismos xilófagos, entre essas, ressalta-se a umidade, a temperatura e o $\mathrm{pH}$ do material [6]. Aprile et al. [1] relata que a madeira encontra-se entre os materiais biológicos de mais difícil decomposição, devido à sua estrutura anatômica e à presença de grandes quantidades de substâncias recalcitrantes, como a lignina, além de outros compostos do metabolismo secundário. Entende-se que a decomposição de materiais biológicos depende de uma série de fatores bióticos e abióticos, tais como as 
condições climáticas, os agentes e sua afinidade com o substrato e assim como as características físicas e químicas do material [7].

Quando atuam na deterioração, os organismos, principalmente fungos, têm um importante papel ecológico na ciclagem de nutrientes para o solo [8], pois atuam diretamente nos componentes primários da madeira [9]. Entretanto, segundo o mesmo autor, esses também são os responsáveis pela destruição de uma grande variedade de produtos a base de madeira, causando significativos prejuízos.

O Brasil, por seu clima tropical e subtropical, propicia uma boa adaptação para muitas espécies exóticas, como Pinus elliottii Engelm., Acacia mearnsii De Wild, Hovenia dulcis Thunb. e a Melia azedarach L., as quais tem colaborado para a diminuição da exploração das matas nativas.

O Pinus elliottii Engelm, popular pinheiro americano, tem sua distribuição geográfica natural nos Estados Unidos da América, sendo considerado como uma das espécies florestais de maior importância. No Brasil teve boa adaptação, sendo que diversos povoamentos tem sido implantados, principalmente, para atender à demanda de madeira para celulose e papel e setor madeireiro [10], suprindo a lacuna deixada no mercado pela escassez gradativa do pinheiro brasileiro (Araucaria angustifolia Bert. O Ktze.) a partir dos anos 60.

A acácia negra (Acacia mearnsii De Wild.), pertencente à família Leguminosae, é uma espécie florestal originária da Austrália, sendo árvore de significativa importância econômica e ornamental e que apresentou boa adaptação na região Sul do Brasil, devido sua tolerância à forte ocorrência de geadas [11]. Apresenta rápida taxa de crescimento e se destaca entre as espécies de maior potencial tanto para a extração do tanino, a partir da casca, como para o uso da madeira, na produção de energia, celulose, papel e chapa de fibra.

A Melia azedarach, espécie de médio porte e pertence à família Meliaceae, conhecida popularmente como Cinamomo, é nativa da Ásia [12]. No Brasil, essa espécie é bastante cultivada, sendo sub-espontânea nas regiões Sul e Sudeste [13]. Um dos fatores que possivelmente justifica o alto grau de adaptação na Região Sul, refere-se ao fato de que o Cinamomo adapta-se a climas frios, tornando viável o aproveitamento de sua matéria prima [14].

A madeira de Cinamomo apresenta semelhança com a de cedro (Cedrela fissilis Vell.), embora seja mais leve. Martinez [14] relatou que essa, bem como outras espécies da família Meliaceae, são conhecidas como produtoras de madeira de excelente qualidade, e se destacam também por possuírem composições químicas similares.

A Hovenia dulcis, pertencente à família Rhamnaceae, é uma espécie arbórea originária do leste da Ásia e vulgarmente conhecida como Uva-do-Japão. Na China ocorre em clima subtropical e temperado quente e úmido. No Brasil, encontra-se sobre tudo nas regiões subtropicais [15]. De acordo com o mesmo autor, além de frutífera, apresenta ótimas perspectivas como madeira, possuindo características físico-mecânicas similares às do louro-pardo (Cordia trichotoma Vell.), e os mais diversos potenciais de utilização, seja na construção civil, marcenaria, vigas, caibros, tábuas, assoalhos, moirões, sendo usada na fabricação de móveis e laminados. Além disso, tem aproveitamento na indústria de celulose e papel e como fonte energética.

Há, portanto, sério interesse na escolha da madeira a ser utilizada, no intuito de prolongar a vida útil de seus subprodutos sem a necessidade de uso de componentes químicos. Desse modo, o presente trabalho teve como objetivo avaliar a durabilidade natural de quatro espécies florestais, Pinus elliottii Engelm., Acacia mearnsii De Wild, Hovenia dulcis Thunb. e a Melia azedarach L., em campo de apodrecimento.

\section{Metodologia}

O experimento foi implantado no município de Frederico Westphalen- RS. Foram utilizadas 20 árvores, cinco para cada espécie, das quais foram confeccionados moirões roliços, com casca, retirados da parte superior das amostras, com dimensões de $1,30 \mathrm{~m}$ de comprimento e em média $12 \mathrm{~cm}$ de diâmetro. As peças foram levadas a campo, em área coberta predominantemente por gramíneas e enterradas verticalmente no solo a uma profundidade de $40 \mathrm{~cm}$ (Figura 1).

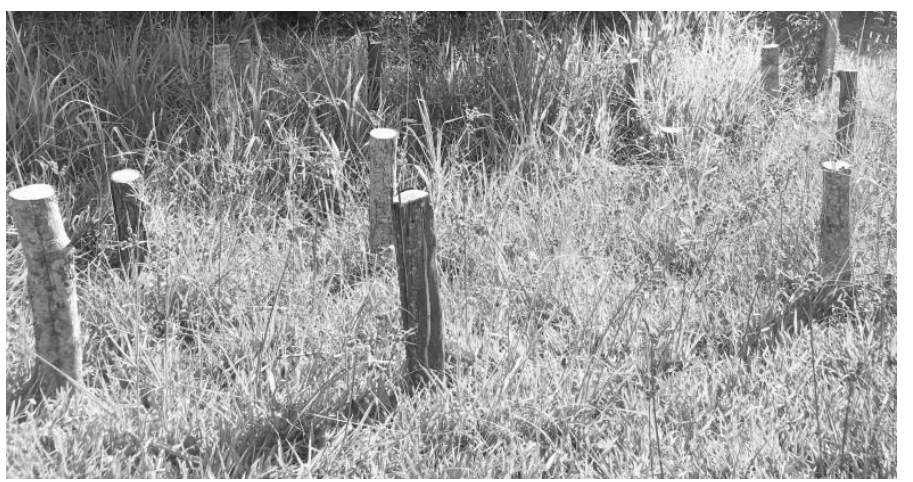

Figura 1- Campo de apodrecimento após a instalação dos moirões

O experimento foi composto por 5 blocos, com uma amostra por bloco, sendo que a disposição das amostras foi realizada aleatoriamente, com espaçamento de $1 \mathrm{~m}$ entre amostras e 1,5 m entre blocos.

Nos períodos de 0,6 e 12 meses foram retirados discos de aproximadamente $10 \mathrm{~cm}$ de espessura (Figura 2), que foram pesados e, posteriormente, colocados em estufa a $103{ }^{\circ} \mathrm{C}$, onde permaneceram até atingir peso constante e condição anidra. A partir deste procedimento foi determinado o teor de umidade das peças. 


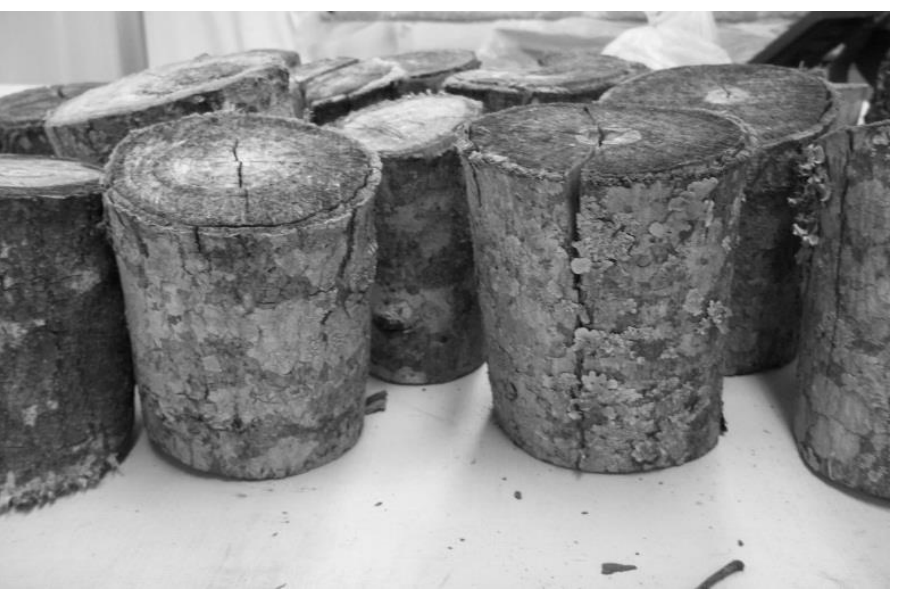

Figura 3 - Discos utilizados na determinação do teor de umidade das peças.

Através de idas a campo mensais, foram realizadas inspeções visuais para verificar o estado das peças e o desenvolvimento de organismos xilófagos.

Em laboratório, o grau de deterioração dos moirões foi feito por meio da solubilidade da madeira em hidróxido de sódio $(\mathrm{NaOH})$ a $1 \%$. Que foi obtida através da norma NBR7990 [16] onde das amostras já reduzida em serragem, pesou-se 2 gramas, nestas foram adicionados $100 \mathrm{~mL}$ de solução de $\mathrm{NaOH} 1 \%$, e em seguida foram encaminhadas para o banho-maria, a aproximadamente $100^{\circ} \mathrm{C}$, por 1 hora, sendo agitadas rapidamente com bastão de vidro nos tempos de 10, 15 e 25 minutos após o início. Transcorrido o período, o material foi transferido para um sistema de filtração a vácuo, onde as amostras foram lavadas primeiramente com água destilada quente, depois com $50 \mathrm{~mL}$ de ácido acético a $10 \%$ e novamente com água destilada quente, filtrando a amostra. O papel filtro resultante foi transferido para um cadinho e seco em estufa a $103^{\circ} \mathrm{C}$ até atingir peso constante. Sendo este procedimento realizado em triplicata para que houvesse maior confiabilidade dos dados. Para a obtenção final da solubilidade da madeira foi utilizada a fórmula 1 , descrita a seguir:

$$
\text { Solubilidade }=[(\mathrm{Pac}-\mathrm{Pc}) / \mathrm{Pas}]^{* 100}
$$

Onde: cadinho;

Pac: peso da amostra + peso do papel filtro + peso do

Pc: peso d papel filtro + peso do cadinho;

Pas: peso da amostra seca;

Os dados obtidos de solubilidade em hidróxido de sódio em função do tempo, para cada espécie analisada, foram submetidos à analise de variância para o delineamento experimental blocos ao acaso e, no caso de rejeição da hipótese de igualdade de médias, ao teste DMS (Diferença Mínima Significativa, $a=5 \%$ ), pelo programa Statgraphics Plus.

\section{Resultados e discussões}

O teor de umidade das espécies determinado nos períodos de 0,6 e 12 meses, pode ser observado na Tabela 1 .

Tabela 1 - Teores de umidade determinados no decorrer do experimento.

\begin{tabular}{ccccc}
\hline Período & Acácia (\%) & Pinus (\%) & Cinamomo (\%) & $\begin{array}{c}\text { Uva-do- } \\
\text { Japão (\%) }\end{array}$ \\
\hline Início & 29,52 & 31,46 & 29,4 & 30,5 \\
\hline 6 meses & 12,68 & 46,41 & 16,7 & 14,7 \\
\hline 12 meses & 23,19 & 42,79 & 18,43 & 21,45 \\
\hline
\end{tabular}

$\mathrm{Na}$ Tabela 1 observa-se que os valores apresentados no início do experimento se encontravam sempre em torno dos $30 \%$, indicando a saturação das fibras e a presença de água livre ou capilar, típica de madeiras verdes. Aos 6 meses de experimento, os teores de umidade se mostraram menores em todos os casos, exceto para o Pinus. No final do experimento, os teores voltaram a se elevar, ou mantiveram-se elevados no caso do Pinus.

Segundo Cruz [17], uma habitual fonte de problemas para a madeira reside no contato com a água ou umidade ambiente elevada que potencializa o risco de degradação desse material por determinados agentes biológicos, no sentido em que esses só atacam quando o teor de água atinge determinados valores. Especificamente, quando as peças permanecem nessas condições por períodos longos, pode ser atacada por fungos ou por térmitas subterrâneas que dela se alimentam.

De acordo com estudos de Alves e Mendes [18], o elevado teor de umidade da madeira é o fator mais importante no processo de deterioração, sendo esse ótimo para o desenvolvimento principalmente de fungos, quando se encontra acima de $45 \%$.

$\mathrm{Na}$ primeira análise visual, realizada a campo, foi verificado que os moirões, de Cinamomo e Uva-do-Japão, emitiram brotações, as quais perduraram até a segunda avaliação. Essa observação torna-se importante para o estudo da ocorrência de certos agentes que são atraídos por compostos emitidos por reações químicas que são desencadeadas no processo da degradação da madeira e que proporcionam boas condições para o desenvolvimento de alguns fungos simbiontes e, consequentemente, de insetos. Quando a madeira se encontra fisiologicamente ativa, essa degradação é comprometida, logo, as reações químicas desencadeadas por esse processo também, afetando dessa forma a atração aos insetos [19], fato que explica o retardo na ocorrência de organismos xilófagos durante o experimento.

Durante as avaliações realizadas a campo, foi constatado, a partir do $8^{\circ}$ mês, o início do ataque de uma única variedade de fungo, identificado como Pycnoporus sanguineus (Pers. ex Fr.) Murr. (Figura 04). Um basidiomiceto conhecido popularmente como orelha-de-pau, causador da podridão branca em madeiras, normalmente é encontrado em áreas tropicais e subtropicais, alimentando-se saprofiticamente de algumas 
espécies de madeira, possui rápida propagação no meio ambiente devido a grande produção de esporos [20] sendo importante causador da perda de massa e da resistência diferentes espécies de madeira [21].

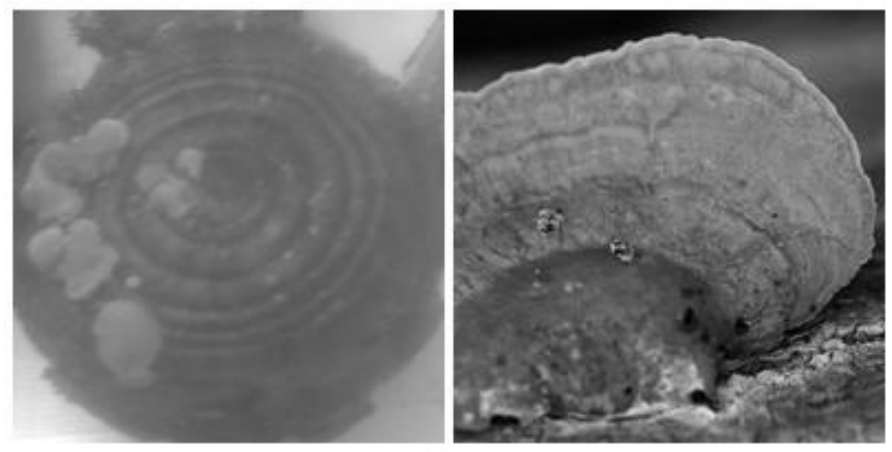

Figura 3- Pycnoporus sanguineus, variedade de fungo apodrecedor observada durante o experimento.

$\mathrm{O}$ ataque pelo fungo foi identificado apenas em duas das espécies avaliadas, na Acácia e no Pinus, tendo sido essas que apresentaram o maior teor de umidade final, fator que pode explicar a ocorrência do agente.

Devido à inobservância de outros organismos, a degradação ocorrida na madeira pode ter sido em decorrência da atuação de agentes atmosféricos, sobretudo luz solar e precipitação pluviométrica, as quais, segundo Cruz [17], provocam alterações de cor e textura, que se traduzem na tonalidade acinzentada da madeira "velha". Essas alterações consistem numa decomposição química de seus compostos por ação da radiação ultravioleta, eventualmente alternada pela lavagem da camada degradada, e foram observadas nas últimas inspeções realizadas a campo.

Durante o tempo em que os moirões ficaram expostos ao campo de apodrecimento, ocorreram variações consideráveis na composição química das espécies, como mostra a Tabela 2.

Tabela 2 - Solubilidade da madeira em hidróxido de sódio encontrada no decorrer do experimento, para as espécies analisadas.

\begin{tabular}{ccccc}
\hline Período & Acácia (\%) & Pinus (\%) & Cinamomo (\%) & $\begin{array}{c}\text { Uva-do- } \\
\text { Japão (\%) }\end{array}$ \\
\hline Início & $25,4 \mathrm{a}^{*}$ & $19,9 \mathrm{a}$ & $28,0 \mathrm{a}$ & $30,5 \mathrm{a}$ \\
\hline 6 meses & $30,7 \mathrm{~b}$ & $31,9 \mathrm{~b}$ & $18,6 \mathrm{~b}$ & $20,7 \mathrm{~b}$ \\
\hline 12 meses & $35,7 \mathrm{c}$ & $29,1 \mathrm{~b}$ & $33,3 \mathrm{c}$ & $34,2 \mathrm{c}$ \\
\hline *Médias seguidas por letras & $\begin{array}{c}\text { iguais, na mesma coluna, não diferem } \\
\text { estatisticamente pelo teste DMS a 5\% de probabilidade de erro. }\end{array}$
\end{tabular}

Nas peças de acácia a solubilidade se elevou ao longo de todo o período. No pinus o aumento ocorreu apenas no primeiro semestre mantendo-se quase que constante posteriormente. Já para o cinamomo e a uva-do-Japão, as porcentagens diminuíram na segunda análise e ao final voltaram a se elevar. Os valores foram analisados pela ANOVA, como blocos ao acaso, sendo que houve diferença significativa apenas entre os tratamentos $(0$, 6 e 12 meses) e não entre os blocos.

A diferença significativa entre os tratamentos foi comprovada através dos valores bem elevados dos P-Value, todos acima dos $5 \%$ de probabilidade de erro considerados no estudo, sendo 0,0065; 0,0140; 0,6218 e 0,1217, para a acácia, uva-do-Japão, cinamomo e pinus, respectivamente.

$\mathrm{O}$ aumento na solubilidade da madeira é possível, pois a solução de $\mathrm{NaOH}$ a $1 \%$ extrai carboidratos de baixo peso molecular, constituídos basicamente de polioses e celulose degradada, podendo indicar o grau de degradação por fungos, calor, luz, oxidação, entre outros, sendo que, na madeira degradada, a porcentagem de materiais solúveis em $\mathrm{NaOH}$ a $1 \%$ aumenta [22]. Fato verificado nas peças de Acácia e Pinus, que indicaram a ocorrência não apenas da perda dos componentes extrativos da madeira, como também a degradação dos componentes da parede celular por agentes deterioradores.

O fenômeno de menor solubilidade da madeira após 6 meses de experimento, ocorrida para o Cinamomo e Uva-doJapão, é explicado por Brand e Muñiz [23] como sendo resultado da oxidação dos ácidos graxos dienóicos e trienóicos, por certas enzimas (liposidases), indicando que houve somente perda dos componentes extrativos da madeira, sem degradação dos componentes da parede celular por agentes de biodegradação. No entanto, considerando apenas a solubilidade final do experimento, as espécies tiveram seus percentuais de solubilidade elevados, indicando também a degradação da parede celular.

A decomposição de materiais biológicos está relacionada a uma série de fatores abióticos, como as condições climáticas, composição da comunidade decompositora, afinidade com o substrato e as características do material exposto. Esses elementos quando correlacionados fecham o ciclo da deterioração, sendo ainda preciso acrescentar a ação do sol sobre a madeira, que gera uma variação de temperatura e nas tensões criadas pelo umedecimento e secagem, tornando-se contribuintes no processo [24].

Analisando-se os valores de solubilidade encontrados e considerando que quanto maior a solubilidade, maior a degradação e menor a durabilidade natural, verificou-se que a espécie, estudada, mais resistente é o Pinus, (mesmo sofrendo o ataque do fungo Pycnoporus Sanguineus), seguido pelo Cinamomo, Uva-do-Japão e a Acácia, que se mostrou a menos resistente.

\section{Conclusões}

Com os dados obtidos no trabalho, pode-se observar que as peças se mantiveram com teores altos de umidade, no decorrer do tempo, porém, mesmo em condições favoráveis, houve a ocorrência de um único fungo, Pycnoporus sanguineus causador 
da podridão branca, atuando na degradação das peças de acácia e pinus, sendo que as demais não foram atingidas.

As análises da solubilidade em hidróxido de sódio demonstraram que a composição química da madeira, das espécies analisadas, sofreu alterações consideráveis com o tempo de exposição ao campo de apodrecimento. Tais alterações ocorreram não apenas nos extrativos, como também a nível de parede celular, o que é demonstrado pelo aumento da solubilidade ao longo do período de exposição.

\section{NATURAL DEGRADATION OF FOUR FOREST SPECIES IN OF DECAYING FIELDS}

ABSTRACT: The objective was to evaluate the natural durability of four forest species (Pinus elliottii, Acacia mearnsii, Hovenia dulcis and Melia azedarach) in decaying field. The experiment was established in the city of Frederico Westphalen RS, being used 20 trees, 5 for each analyzed species, which have been transformed into plump fence posts buried at a depth of 40 $\mathrm{cm}$ from the ground. In the periods 0,6 and 12 months discs were removed for the determination of moisture content and conducting chemical analyzes. With monthly inspections to field, visual evaluations were performed to check the status of parts and the development of wood-destroying organisms. In the laboratory, determining the degree of deterioration was performed by the solubility of the wood in a $1 \%$ sodium hydroxide. The procedures were performed in triplicate and analyzed statistically by the Tukey test at $5 \%$ error probability. The results showed that the moisture content remained high throughout the experiment. In the visual assessments it has been found the occurrence of a single fungus, Pycnoporus sanguineus, at Acacia mearnsii and Pinus elliottii. The exposure time has caused significant changes in the chemical composition of the species indicated by the increased solubility of the timber.

Keywords: Solubility. Extractives. Wood-boring insects. Moisture. Decay.

\section{Referências}

[1] APRILE, F. M.; DELITTI, W. B. C.; BIANCHINI JÚNIOR, L. Aspectos cinéticos da degradação de laminados de madeira em ambientes aquático e terrestre. Revista Brasileira de Biologia, v.59, n.3, p.485-492, 1999.

[2] PAES, J. B. Resistência natural de madeira de Corymbia maculata (Hook.) K.D. Hill \& L.A.S. Johnsos a fungos e cupins xilófagos, em condições de laboratório. Revista Árvore, v.26, n.6, p.761-767, 2002.
[3] BOTELHO, G. M. L.; SANTANA, M. A. E.; ALVES, M. V. S. Caracterização química, durabilidade natural e tratabilidade da madeira de seis espécies de eucalyptos plantados no Distrito Federal. Revista Árvore, v.24, n.1, p.115-121, 2000.

[4] SILVA, L. F. da; WANDERLEY, M. B.; PAEZ, J. B.; JESUS, W. C. Determinação da resistência natural da espécie Eucalyptus cloeziana F. Muell em condições de laboratório. In: XIV ENCONTRO LATINO AMERICANO DE INICIAÇÃO CIENTÍFICA E X ENCONTRO LATINO AMERICANO DE PÓS-GRADUAÇÃO, 2011. São José dos Campos. Anais... São José dos Campos: Universidade do Vale do Paraíba, 2011.

[5] JESUS, M. A.; MORAIS, J. W.; ABREU, R. L. S. Durabilidade natural de 46 espécies de madeira amazônica em contato com o solo em ambiente florestal. Scientia Forestalis, n. 54, p. 81-92, 1998.

[6] TEXEIRA, D. E.; COSTA, A. F.; SAnTANA, M. A. E. Aglomerado de bagaço de cana-deaçucar: resistência natural aos apodrecedores. Scientia Forestalis, n.52, p.29-34, 1997.

[7] SWIFT, M. J.; HEAL, D. W.; ANDERSON, J. M. Studies in Ecology-Decomposition in Terrestrial and Aquatic Ecosystems. Oxford: Blackwell, 1979.

[8] OLIVEIRA, A. M. F.; LELIS, A. T. de; LEPAGE, E. S.; LOPEZ, G. A. C.; OLIVEIRA, L. C. S. de; CAÑEDO, M. D.; MILANO, S. Agentes destruidores da madeira. In LEPAGE, E. S. (Coord.) Manual de preservação de madeiras. São Paulo: IPT, SICCT, 1986. p.99-278..

[9] BARILLARI, C. T. Durabilidade da madeira do gênero Pinus tratada com preservantes: avaliação em campo de apodrecimento. 2002. 79f. Dissertação (Mestrado em Recursos Florestais) Escola Superior de Agricultura Luiz de Queiroz, Piracicaba, 2002.

[10] DRESCHER, R.; SCHNEIDER, P. R.; FINGER, C. A. G.; QUEIROZ, F. L. C. Fator de forma artificial de Pinus elliottii Engelm para a região da Serra do Sudoeste do Estado do Rio Grande do Sul. Ciência Rural, v.31, n.1, 2001.

[11] ROVERSI, T.; MATTEI, V. L.; SILVEIRA JÚNIOR, P.; FALCK, G. L. Superação da dormência em sementes de Acácia negra (Acacia Mearnsii De Willd.). Revista brasileira de Agrociência, v.8, n.2, Mai/Ago, p. 161-163, 2002.

[12] CABEL, S. R. Micropopagação do Cinamomo (Melia azedarach L.) 2006. 96 f. Dissertação (Mestrado em Agronomia) - Universidade Federal do Paraná, Curitiba, 2006.

[13] LORENZI, H. Árvores exóticas do Brasil: madeireiras, ornamentais e aromáticas. Nova Odessa: Instituto Plantarum, 2003. 382 p. 
[14] MARTINEZ, S. S. O NIM - Azadirachta indica: natureza, usos múltiplos, produção. Instituto agronômico do Paraná. Londrina: IAPAR, 2002. p. 142., Versão 3.02, Infometrix, Seattle, WA, 1990-2001.

[15] CARVALHO, P. E. R. Ecologia, silvicultura e usos da Uvado-japão. Colombo: EMBRAPA, CNPF, 1994. p.24.

[16] ASSOCIAÇÃO BRASILEIRA DE NORMAS TÉCNICASABNT. NBR 7990 - Madeira - Determinação do material solúvel em hidróxido de sódio a 1\%. Rio de Janeiro, 2010.

[17] CRUZ, H. Patologia, avaliação e conservação de Estruturas de madeira. Santarém: Núcleo de Estruturas de Madeira, Laboratório Nacional de Engenharia Civil, 2001.

[18] ALVES, M. V. da S.; MENDES, A. de S. Biodegradação e preservação da madeira. Brasília: LPF, 2002. p.41.

[19] TREVISAN, H ; TIEPPO, F. M. M.; CARVALHO, A. G. Degradação natural de toras de cinco espécies florestais em dois ambientes. Floresta (UFPR), v. 38, p. 33-41, 2007

[20] BENINCA, C. P. Indução de fitoalexinas e atividade de peroxidases em sorgo e soja tratados com extratos de basidiocarpos de Pycnoporus Sanguineus. 2007. 45f. Dissertação (Mestrado em Agronomia) - Universidade Estadual do Oeste do Paraná, Marechal Cândido Rondon, 2007

[21] ALVES, M. V. da S.; COSTA, A. F.; ESPIG, D. S.; VALE, A. T. Resistência natural de seis espécies de madeiras da região Amazônica a fungos apodrecedores, em ensaios de laboratório. Revista Ciência Florestal, v.16, n.1, p.17-26, 2006.

[22] GRASSI, A. C.; TOMAZELI, A. J. T.; GRASSMANN, A.; TREVISAN, R. WASTOWSKI, A. D.; ROSA, G. M. da. Resistência natural da madeira de Pinus elliottii Elgelm em campo de apodrecimento. In: XXII MOSTRA DE INICIAÇÃO CIENTÍFICA, 2012. Passo Fundo. Anais... Passo Fundo: Universidade de Passo Fundo, 2012.

[23] BRAND, M. A.; MUÑIZ, G. I. B. Influência da época de colheita e da estocagem na composição química da biomassa florestal. Floresta e Ambiente, v.19, p.66-78, 2012.

[24] SWIFT, M. J.; HEAL, D. W.; ANDERSON, J. M. Studies in Ecology-Decomposition in Terrestrial and Aquatic Ecosystems.

Oxford: Blackwell, 1979. 371p. 